\title{
Identity, minority stress and psychological well-being among gay men and lesbians
}

\author{
Adam W. Fingerhut ${ }^{\mathrm{a} *}$, Letitia Anne Peplau ${ }^{\mathrm{b}}$ and Shelly L. Gable \\ ${ }^{a}$ Department of Psychology, Loyola Marymount University, Los Angeles, CA, USA; ${ }^{b}$ Department of \\ Psychology, University of California, Los Angeles, CA, USA; ${ }^{c}$ Department of Psychology, University \\ of California, Santa Barbara, CA, USA
}

(Received 11 June 2009; final version received 29 March 2010)

\begin{abstract}
Exposure to gay-related discrimination, perceived stigma or other stressors is associated with poorer mental health for gay and lesbian individuals. Yet not all gay men and lesbians experience the same levels or types of stressors, nor do they react the same in response to stress exposure. Using a sample of self-identified gay and lesbian individuals who completed an online survey, this research examined whether social identity, specifically a sense of belonging to the lesbian, gay and bisexual (LGB) community, predicted both exposure and reactivity to gay-related stress. Results showed that those who were higher in gay identity reported significantly more discrimination but significantly less perceived stigma than those who were lower in gay identity. Although gay identity was not associated with reactivity to discrimination, it was associated with reactivity to perceived stigma. Those who were lower in gay identity reported significantly more depressive symptoms when they experienced high levels of perceived stigma than when they experienced low levels of perceived stigma. In contrast, those who were higher in gay identity were buffered against the negative consequences of perceived stigma; there were no differences in reported depression based on the experiences of perceived stigma. The theoretical and practical implications of these data are discussed.
\end{abstract}

Keywords: gay and lesbian; stress; psychological well-being; gay identity

\begin{abstract}
Although most gay and lesbian individuals are psychologically healthy, gay men and lesbians do experience mental health problems such as depression and anxiety to a greater degree than heterosexuals (for a review, see Cochran, 2001). This disparity may result not from homosexuality itself but from the unique stress experiences that gay men and lesbians face as members of a socially stigmatised minority group (Herek \& Garnets, 2007; Meyer, 1995, 2003). Such stress experiences include exposure to verbal assaults, rejection, violence and other forms of discrimination related to being gay/lesbian. Additionally, gay men and lesbians often report high levels of perceived stigma, that is, fear of being rejected or discriminated against because of their minority status. Although gay-related stress $^{1}$ experiences appear to be common over the course of a lifetime, not all gay men and lesbians experience the same levels of stress, nor do they react in similar ways to stressful events. Why do some gay and lesbian individuals experience more stress than
\end{abstract}

*Corresponding author. Email: afingerh@LMU.edu 
others? Why do some individuals experience negative mental health consequences in the face of gay-related stressors whereas others do not? To begin answering these questions, we utilised Bolger and Zuckerman's (1995) exposure-reactivity framework, which suggests that enduring, stable, trait-level variables such as personality can affect both exposure to stressors and reactivity or the way in which an individual responds to stressors. Specifically, we examined whether social identity, defined as a sense of belonging to the lesbian, gay and bisexual (LGB) community, serves as a moderator variable in the stress process for gay and lesbian individuals, influencing exposure as well as reactivity to gay-related stressors.

\section{Gay-related stress and psychological well-being}

Minority stress has been defined as the stress associated with 'categorically ascribed inferior status and blocked access to legitimate social and economic opportunities' (Brooks, 1981, p. 78). Working within a stress framework, Brooks laid out a sequence of events through which minority identity (e.g. 'African American', 'gay') impacts the biophysical process recognised as stress. Briefly, she argued that the inferior status ascribed to minorities leads to an increase in stressful life events (e.g. discrimination), which in turn leads to threatened self-esteem and a reduced sense of security. This ultimately results in the physiological and psychological experience of stress. Additionally, because people generally retain their minority identity across situations, Brooks contended that they are constantly confronted with inferior status and thus placed in a chronic state of stress. Using a slightly different conceptualisation, Meyer (1995) argued that minority stress arises from 'the juxtaposition of minority and dominant values and the resultant conflict with the social environment ...' (p. 39). Thus according to Meyer's definition, it is not necessarily inferior status but rather conflicting ideologies that cause stress. The end result is the same, however: minority individuals are forced to be hypervigilant in their social environments and are thus placed in a chronic state of stress.

A few researchers have applied the minority stress model to gay men and lesbians (e.g. diPlacido, 1998; Meyer, 1995, 2003). In what is probably the most cited conceptualisation of gay-related stress, Meyer (2003) discussed two distinct categories of gay-related stress. On one hand are distal stressors or stressors that are external to the gay or lesbian individual. Included in this class of stressors are objective events such as overt acts of discrimination. On the other hand are proximal stressors or stressors that arise within the sexual minority individual. Such stressors are more subjective and include both perceptions that one is stigmatised and internalised homophobia, or an internalisation of society's negative evaluation of gays and lesbians.

Research has consistently demonstrated the associations between exposure to these gay-related stressors and lower levels of well-being in samples of sexual minority individuals. In a cross-sectional study of HIV-negative gay men conducted in the late 1980s, Meyer (1995) examined the relationships between discrimination, perceived stigma and internalised homophobia, on the one hand, and psychological distress as measured by demoralisation, guilt, suicide ideation, AIDS-related traumatic stress responses and sex problems, on the other hand. As predicted, men with higher levels of the three minority stressors were more likely to experience negative health outcomes. Additionally, each of the stressors was independently related to the five measures of psychological distress, demonstrating that each stressor is in fact a unique contributor to the overall experience of chronic stress related to sexual orientation. Using a convenience sample of gay, lesbian, and bisexual men and women predominantly from Virginia, Lewis, Derlega, Berndt, Morris, and Rose (2001) found a positive correlation between the amount of gay-related 
stress exposure and depressive symptoms as assessed by the Center for Epidemiological Studies Depression (CES-D) Scale.

In one of the few studies to use population-based sampling through random digit dialling, Mays and Cochran (2001) documented similar patterns as those seen in studies using convenience sampling. Specifically, experiences of discrimination were positively associated with having any type of psychiatric disorder, with rating one's current mental health as 'fair' or 'poor' (as opposed to 'good', 'very good' or 'excellent') and with having high current psychological distress. Finally, in line with findings based on retrospective reports, Swim, Pearson, and Johnston's (2004) prospective daily experience study of LGB adults revealed that more frequent experience with heterosexist hassles on a given day resulted in poorer end-of-day mood including significantly more anger and more anxiety.

\section{Gay identity and the stress process}

Data demonstrate that gay and lesbian individuals experience gay-related stressors and that these stressors are associated with poorer mental health outcomes. At the same time, it is clear that there are individual differences in the amount and types of stressors to which gay men and lesbian women are exposed as well as differences in how gay and lesbian individuals respond to the stressors. Although many factors, including social support and personality, may affect exposure and reactivity to stressors for sexual minorities (Szymanski, 2009), we focused on the role of gay identity ${ }^{2}$ because research has consistently demonstrated that social identities have a powerful influence on the lives of minority individuals. Such identities have been shown to affect how individuals perceive their social environment (Hong, Morris, Chiu, \& Benet-Martínez, 2000), how they perform in exams (Schmader, 2002; Steele \& Aronson, 1995) and how they relate to other individuals from similar and different groups (Tajfel \& Turner, 1979). Of particular importance for the research presented here is evidence that gay identity has direct links with psychological well-being and with stress exposure.

\section{Gay identity and psychological well-being}

Gay men and lesbians who are more strongly gay-identified have been shown to fare better in terms of mental health. This association holds across a variety of operationalisations of identity, including measures of identity commitment, participation in activities related to the LGB community and degree of identity disclosure. Using a sample of gay and bisexual men in the Chicago area, Frable, Wortman, and Joseph (1997) showed that those who had a positive gay identity and who had strong connections to the LGB community felt more positive about themselves. In a sample of lesbian women from California, Fingerhut, Peplau, and Ghavami (2005) similarly showed that those who were more gay-identified, assessed through a composite scale measuring affective, cognitive and behavioural components of lesbian identity, scored higher on a measure of life satisfaction.

\section{Gay identity and exposure to gay-related stress}

Researchers have also shown that gay identity is associated with both distal stressors (e.g. discrimination) and proximal stressors (e.g. perceived stigma). Consistently, those who are highly identified with the LGB community report more discrimination than those who are less identified. In a survey of gay and bisexual men from three cities in the Southwestern United States, Huebner, Rebchook, and Kegeles (2004) found that those men who were 
more 'out' were 1.45 times more likely to report experiencing verbal harassment and were 1.73 times more likely to report discrimination. As part of a dissertation on prejudice and well-being in lesbian women, Selvidge (2001) found a significant positive relationship between outness and experiences with gay-related discrimination. Finally, in a community sample of gay and lesbian individuals from the Northeast and Midwest, Waldo (1999) found that those who disclosed their gay identity to a wide circle of people experienced more gay-related discrimination than those who disclosed to a much smaller group of people. In discussing possible links between identity and discrimination, Meyer (1995) noted that 'as gay men and lesbians become more visible, they increasingly become targets of anti-gay violence, prejudice and discrimination' (p. 41).

Although research on perceived stigma is much less common than research on discrimination, those studies examining connections between gay identity and perceptions of stigma have produced a fairly consistent picture: high identification with the LGB community is associated with lower levels of perceived stigma. In their study of gay and bisexual men, Frable et al. (1997) showed that 'outness' was negatively related to perceptions of stigma from society in general and from the family in particular. In other words, those who were out to the majority of their social network were less likely to agree with such statements as 'Most heterosexuals feel disgusted or repelled by homosexuals' or 'Most heterosexuals break off relationships with homosexuals'. In a study of South African gay men (Theuninck, 2000), participation in gay organisations was negatively related to expectations of being rejected by family, friends and people at work and to perceptions of stigma assessed with the Homosexual Devaluation and Discrimination Scale. Although the direction of the effects is unknown in these studies, it is possible that stronger ties to one's gay identity allow individuals to ward off cultural messages that demonise or stigmatise.

\section{Gay identity, gay-related stress and psychological well-being}

In addition to direct links between gay identity, on the one hand, and psychological wellbeing and gay-related stressors, on the other, identity may moderate the link between stress and well-being. In other words, gay identity may affect reactivity. To date, researchers have not examined this possibility among gay and lesbian individuals. ${ }^{3}$ Despite this void, a small body of research with ethnic minority individuals has demonstrated that identity can serve as a buffer in the face of stress, positively altering the link between stress and well-being. Sellers and colleagues (Neblett, Shelton, \& Sellers, 2004; Sellers, Caldwell, Schmeelk-Cone, \& Zimmerman, 2003; Sellers \& Shelton, 2003), for example, found that African Americans whose ethnic identity was more central to their overall identity experienced better psychological health in the face of discrimination than those whose ethnic identity was not central. Similarly, Mossakowski (2003) demonstrated that, for a sample of Filipino Americans, ethnic identity buffered the association between both lifetime and recent discrimination and depressive symptoms.

We believe that identity likely serves a similar buffering role in the stress process for sexual minorities. Those gay and lesbian individuals who are more gay-identified likely have a greater sense of self, which can help in coping with gay-related stressors. Additionally, individuals who are more connected to the LGB community have access to valuable social support resources, both tangible and emotional, which can be utilised during times of stress. Social support from the LGB community may be especially important when the stressors are gay-related, as members of the LGB community are part of an in-group that understands this specific type of stress. We believe this is true regardless of whether 
the particular stressor is distal (e.g. discrimination) or proximal (e.g. perceived stigma). Furthermore, identity should have similar buffering effects regardless of the nature of the gay-related stressor.

\section{Summary}

Although the majority of gay and lesbian individuals lead healthy and satisfying lives, research consistently demonstrates significant mental health disparities between gay men and lesbians and their heterosexual counterparts. Researchers have shown that the mental health issues present in the LGB community are partially a product of experiences with stressors related to minority status. Greater exposure to discrimination and perceptions of stigma have been linked with poorer mental health in sexual minority individuals. Little is known, however, about individual differences that influence who is most likely to experience gay-related stressors and who reacts negatively versus positively in the face of such stressors. This research tests the idea that gay identity is associated with both exposure to stress and reactivity to gay-related stressors.

A large cross-sectional study assessed gay identity, exposure to distal stressors (gayrelated discrimination), exposure to proximal stressors (gay-related perceived stigma) and psychological well-being. Importantly, although previous research has grouped gay, lesbian and bisexual participants together, this study examined the experiences only of gay men and lesbian women. Although gay and lesbian individuals participate in a larger LGB community, it is becoming clear that their experiences are notably different from their bisexual peers. Research has shown, for example, that bisexual individuals tend to report poorer mental health than gay men and lesbians (e.g. Robin et al., 2002; Udry \& Chantala, 2002). In a review of research concerning mental health among bisexual individuals, Dodge and Sandfort (2007) concluded that a major limitation of current research on sexual-minority mental health has been an 'inability to distinguish bisexual individuals from homosexual individuals ...' (p. 31). We chose to disentangle these experiences and to focus exclusively on the experiences of gay and lesbian individuals.

The following predictions were tested:

(1) Greater exposure to discrimination and to perceived stigma will both be associated with poorer psychological well-being.

(2) Gay identity will be associated with psychological well-being such that those who are higher in gay identity will report higher psychological well-being than those who are lower in gay identity.

(3) Gay identity will be associated with stress exposure such that those who are higher in gay identity will report experiencing more discrimination and less perceived stigma than those who are lower in gay identity.

(4) Gay identity will be associated with stress reactivity such that those who are higher in gay identity will be buffered against the negative effects of stress whereas those lower in gay identity will not be.

\section{Method}

To examine the associations among identity, gay-related stressors and psychological wellbeing, a cross-sectional survey was conducted in which gay and lesbian participants completed questions assessing identifications with the LGB community, experiences with discrimination and perceived stigma and current psychological well-being. 


\section{Participants}

Self-identified gay and lesbian individuals (188 women, $261 \mathrm{men}$ ) participated in an online survey concerning sexual orientation and daily life experiences. Participants ranged in age from 18 to $76(M=32.86, \mathrm{SD}=12.08)$ and were primarily Caucasian $(4 \%$ African American/black, 1\% Asian/Asian American, 85.5\% Caucasian, 3.8\% Latino/a, 2\% Native American, 5.5\% biracial/other). Participants were recruited online and were from a variety of states in the United States. Approximately 20\% $(N=100)$ of the participants came from California. Other states providing a sizable number of participants included North Carolina $(N=36)$, Arizona $(N=35)$, Michigan $(N=35)$ and Florida $(N=31)$.

\section{Materials}

Participants completed an online survey that was created using the popular survey-hosting site, http://www.surveymonkey.com/. Key measures are described below.

\section{Gay identity}

To assess gay identity, an adapted version of Phinney's (1992) Multi-Ethnic Identity Measure (MEIM) was used. Specifically, we used the seven items from the MEIM-R (Roberts et al., 1999) that measure one's sense of affirmation and belonging. Participants rated on a $1-5$ scale ( $1=$ strongly disagree; $5=$ strongly agree $)$ the extent to which they agree or disagree with such items as 'I have a strong sense of belonging to the gay/lesbian/ bisexual community'; 'I feel good about being gay/lesbian'. Participants' scores indicate that on average they were highly identified with the LGB community $(M=4.04$, $\mathrm{SD}=0.76$ ). The scale was highly reliable, $\alpha=0.90$.

\section{Schedule of homophobic events}

Items from the Schedule of Racist Events scale (Landrine \& Klonoff, 1996) were reworded to apply to discrimination based on sexual orientation. Participants rated on a 1-6 scale ( $1=$ never; $6=$ almost all of the time) how often a variety of incidents had occurred to them over the course of their life. Sample incidents include being 'treated unfairly by coworkers, fellow students and colleagues because of your sexual orientation'; being 'treated unfairly by strangers because of your sexual orientation' and being 'called a homophobic name such as fag (dyke)'. This adapted version of the scale proved highly reliable in the current sample $(\alpha=0.93, M=2.03, \mathrm{SD}=0.71)$.

\section{Homosexual devaluation and discrimination scale}

Link (1987) originally designed this 11-item scale to measure perceived stigma among psychiatric patients. Others (Ortiz, 2001; Theuninck, 2000) revised the scale to measure perceptions of societal attitudes regarding homosexuality. Participants rated on a $1-5$ scale ( $1=$ strongly disagree; $5=$ strongly agree) the extent to which they agree or disagree with such statements as 'Most people would willingly accept a gay man as a close friend (reverse scored)' and 'Most people feel that homosexuality is a sign of personal failure'. The alpha was $0.85(M=2.94, \mathrm{SD}=0.63)$.

\section{Psychological well-being}

Psychological well-being was assessed with the 20-item CES-D Scale (Radloff, 1977). Using a 4-point scale $(1=$ less than 1 day; $4=5-7$ days $)$, participants indicated the 
frequency with which they felt or behaved in a certain way over the past week. For example, participants indicated how frequently they 'didn't feel like eating' and 'felt depressed'. The alpha for this scale was $0.92(M=1.57, \mathrm{SD}=0.53)$.

\section{Demographic characteristics}

Participants indicated their age, gender, ethnicity and sexual orientation (choosing from a list including gay, lesbian, heterosexual, bisexual or other).

\section{Procedure}

Calls for participation, which stated that individuals were needed for a study on experiences with the LGB community, were e-mailed to a variety of LGB-focused organisations. Attempts were made to reach a wide range of organisations to attract participants who might vary in their identification with the LGB community. The calls for participation included a web address, which interested individuals could access to learn more about the study and to begin participation. After agreeing to participate, individuals completed a series of standardised measures assessing the critical constructs. Upon completing the survey, participants indicated one of five charities to receive a donation in appreciation for their participation.

\section{Results}

Correlations among the main variables are shown in Table 1. Because age correlated with some of the constructs of interest, the regression analyses presented below controlled for age. Comparisons ( $t$-tests) were made between men and women on all the constructs of interest; results revealed no gender differences in gay identity, reported discrimination, perceived stigma or depressive symptoms. For this reason, we did not control for gender in the analyses. ${ }^{4}$

\section{Gay-related stress and gay identity and links with psychological well-being}

We predicted that greater exposure to discrimination and perceived stigma would be associated with poorer psychological well-being. Separate analyses were conducted to examine associations between discrimination and depressive symptoms and between perceived stigma and depressive symptoms. Above and beyond age, experiences with discrimination were associated with depressive symptoms, $R^{2}=.06, \Delta R^{2}=.02, \Delta F(1,357)=6.91$, $p<.01$. More specifically, higher levels of discrimination were associated with higher levels of depressive symptoms $(\beta=0.14, p<.01)$. Similarly, experiences with perceived stigma were associated with depression, $R^{2}=.11, \Delta R^{2}=.07, \Delta F(1,356)=26.22$,

Table 1. Correlations among main variables.

\begin{tabular}{lccccc}
\hline & 1 & 2 & 3 & 4 & 5 \\
\hline (1) Age & 1.00 & & & & \\
(2) Gay identity & $0.13^{*}$ & 1.00 & & & \\
(3) Discrimination & 0.004 & $0.15^{* *}$ & 1.00 & & \\
(4) Perceived stigma & -0.02 & $-0.15^{* *}$ & $0.34^{* *}$ & 1.00 & \\
(5) Depressive symptoms & $-0.21^{* *}$ & $-0.33^{* *}$ & $0.14^{* *}$ & $0.25^{* *}$ & 1.00 \\
\hline
\end{tabular}

Note: ${ }^{*} p<.05,{ }^{* *} p<.01$. 
$p<.001$. Higher levels of perceived stigma were associated with higher levels of depressive symptoms $(\beta=0.26, p<.001)$.

A second prediction was that those who were higher in gay identity would report better psychological well-being. As predicted, those who were higher in gay identity reported lower levels of depressive symptoms $(\beta=-0.30, p<.001)$.

\section{Gay identity and exposure to gay-related stress}

Next, associations between gay identity and stress exposure were examined. We predicted that those who were higher in gay identity would report more discrimination and less perceived stigma than those who were lower in gay identity. Results showed that gay identity was associated with exposure to the distal stressor of discrimination, $R^{2}=.02, \Delta R^{2}=.02$, $\Delta F(1,358)=8.92, p<.01$, and the proximal stressor or perceived stigma, $R^{2}=.02$, $\Delta R^{2}=.02, \Delta F(1,357)=8.10, p<.01$. As predicted, in contrast to those lower in gay identity, those who were higher in gay identity reported more exposure to discrimination $(\beta=0.16, p<.01)$ and less exposure to perceived stigma $(\beta=-0.15, p<.01)$.

\section{Gay identity, gay-related stress exposure and psychological well-being}

We predicted that gay identity would buffer participants against the negative effects of stress exposure. In other words, those higher in gay identity would react better in the face of gay-related stressors (both discrimination and perceived stigma) than those lower in gay identity. To test this prediction, stepwise linear regression analyses were used to examine the interaction between gay identity and stress exposure in predicting depressive symptoms. Step 1 included the covariate construct of age. Step 2 included the main effects of gay identity and stress exposure (analyses were conducted separately for discrimination and perceived stigma). Step 3 included the interaction between gay identity and stress exposure, which was calculated as the product of the centred scores for gay identity and each of the stressors.

Results for the full regression models are presented in Tables 2 and 3. In contrast to prediction, gay identity did not interact with discrimination in predicting depressive symptoms. However, as can be seen in Figure 1, gay identity did interact with perceived stigma in predicting depressive symptoms, $R^{2}=.20, \Delta R^{2}=.02, \Delta F(1,348)=8.81, p<.01$; $\beta=-0.15, p<.01$. To better understand this effect, we used the procedures described by Aiken and West (1991) for examining the interaction effects in regression. Specifically, we examined the significance of the slopes for the perceived stigma regression lines for those higher in gay identity versus those lower in gay identity. We computed the standard errors for the simple slopes and conducted $t$-tests to determine whether each simple slope was significantly different from zero. These analyses revealed that, among individuals who

Table 2. Stepwise linear regression model for the prediction of depressive symptoms from age, gay identity, discrimination and the interaction between identity and discrimination.

\begin{tabular}{lcccccccc}
\hline Step and variable & $\mathrm{d} f$ & $R^{2}$ & $\Delta R^{2}$ & $\Delta F$ & $B$ & $\mathrm{SE}$ & $\beta$ & $t$ \\
\hline (1) Age & $(1,352)$ & .05 & .05 & $17.19^{*}$ & -0.01 & 0.002 & -0.22 & $-4.15^{*}$ \\
(2) Gay identity & $(2,350)$ & .16 & .12 & $24.40^{*}$ & -0.17 & 0.03 & -0.32 & $-6.44^{*}$ \\
$\quad$ Discrimination & & & & & 0.09 & 0.03 & 0.18 & $3.66^{*}$ \\
(3) Identity $\times$ Discrimination & $(1,349)$ & .16 & .00 & 0.05 & -0.01 & 0.03 & -0.01 & -0.22 \\
\hline
\end{tabular}

Note: ${ }^{*} p<.001$. 
Table 3. Stepwise linear regression model for the prediction of depressive symptoms from age, gay identity, perceived stigma and the interaction between identity and stigma.

\begin{tabular}{lcccccccc}
\hline Step and variable & $\mathrm{d} f$ & $R^{2}$ & $\Delta R^{2}$ & $\Delta F$ & \multicolumn{1}{c}{$B$} & $\mathrm{SE}$ & \multicolumn{1}{c}{$B$} & \multicolumn{1}{c}{$t$} \\
\hline (1) Age & $(1,351)$ & .05 & .05 & $16.95^{* *}$ & -0.01 & 0.002 & -0.22 & $-4.12^{* *}$ \\
(2) Gay identity & $(2,349)$ & .18 & .13 & $28.59^{* *}$ & -0.14 & 0.03 & -0.26 & $-5.32^{* *}$ \\
Perceived stigma & & & & & 0.12 & 0.03 & 0.23 & $4.63^{* *}$ \\
(3) Identity $\times$ stigma & $(1,348)$ & .20 & .02 & $8.81^{*}$ & -0.08 & 0.03 & -0.15 & $-2.97^{*}$ \\
\hline
\end{tabular}

Note: ${ }^{*} p<.01,{ }^{* *} p<.001$.

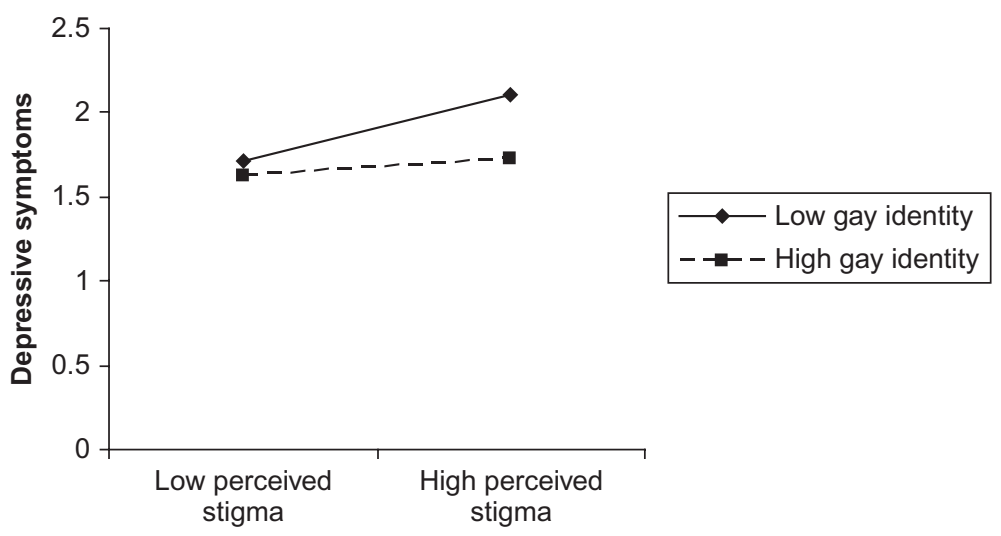

Figure 1. Gay identity moderating associations between perceived stigma and depressive symptoms.

were lower in gay identity, those who experienced higher levels of perceived stigma had higher levels of depressive symptoms than those who experienced lower levels of perceived stigma, $t(348)=4.35, p<.001$. However, for those higher in gay identity, perceived stigma was not associated with depressive symptoms, $t(348)=1.02, p=n s$. As predicted, gay identity, in particular a sense of belonging to the LGB community, buffered participants from the negative effects of proximal stress on psychological well-being.

\section{Discussion}

Although research has consistently demonstrated a link between exposure to gay-related stress and psychological well-being for gay and lesbian individuals, little is known about factors that might influence this association. This study examined the role of social identity, particularly a sense of belonging to the LGB community, in psychological well-being and in exposure and reactivity to gay-related stressors. To begin, results demonstrated that those who were higher in gay identity reported higher levels of psychological well-being. Additionally, and in line with prediction, gay identity was significantly associated with exposure to both the distal stressor of discrimination and the proximal stressor of perceived stigma. In comparison to those lower in gay identity, those higher in gay identity reported greater levels of discrimination and lower levels of perceived stigma.

Taken together, these results strongly suggest that a sense of belonging to one's sexual minority community plays an important role in the psychological lives and stress experiences of gay and lesbian individuals. More research is needed, however. Although gay 
identity was related to stress and well-being, the role of such identification appears complex and needs to be further explored. For example, although strong identification served a protective function, as demonstrated by associations with higher levels of well-being and lower levels of perceived stigma, it simultaneously served as a risk factor, as demonstrated by associations with higher levels of reported discrimination. Thus, a lesbian who is active in the LGB community may be less depressed and perceive less stigmatisation about being lesbian than her peers who distance themselves from the LGB community. But at the same time, she may also perceive more hostile incidents at work or in her daily activities. Clinicians and practitioners working with lesbian and gay clients should be aware of this double-edged sword. Additionally, researchers need to further examine this complexity to better understand the circumstances in which identity may help and the circumstances when it may potentially hurt.

In addition, gay identity also moderated the link between perceived stigma and psychological well-being. For those lower in gay identity, higher levels of perceived stigma were associated with higher levels of depressive symptoms. In contrast, those higher in gay identity were buffered against the negative consequences of perceived stigma. This finding regarding stress buffering is noteworthy, although more research is needed to better understand the mechanism through which this effect occurs. For example, do individuals who are high in gay identity draw upon valuable social support resources, either real or imagined, to downplay the negative evaluation of the LGB community that they sense around them? Might these individuals make different attributions in the face of perceived stigma, blaming other people's ignorance or prejudice rather than internalising the shame? These and other mediating mechanisms need to be studied.

We expected that gay identity would also buffer individuals against the negative consequences of discrimination. However, this prediction was not supported: gay identity did not moderate the effect of discrimination on psychological well-being. This finding stands in contrast to a small set of studies which has demonstrated that ethnic identity buffers ethnic minorities against the harmful effects of discrimination (e.g. Neblett et al., 2004). Perhaps the retrospective assessment of discrimination used in this study was not sufficiently sensitive to capture the phenomenon in question. Our measure assessed the frequency of experiences of discrimination over the course of a lifetime. Identity may play an important role in moderating the effects of gay-related stressors in the immediate situation, but this role may weaken as time passes. Thus, without capturing recent or ongoing experiences of discrimination, it may be impossible to detect the possible buffering effect of gay identity.

Future research examining individual differences in reactivity to gay-related stressors would benefit from the use of more diverse methodologies and measures. Daily experience studies in which individuals record their experiences with discrimination, perceived stigma and well-being each day over several days or weeks may be especially valuable. Through a daily experience study, experiences of discrimination and reactions to such experiences could be captured as they occur. This would allow us to determine whether the lack of a buffering effect for discrimination found in this study was a methodological artefact of using retrospective reports. Second, the longitudinal nature of a daily experience study would permit a closer examination of the causal sequence of events involved in the stress process for gay and lesbian individuals. These data are important and novel in demonstrating that identity is associated with differences in exposure and reactivity to stress; however, they cannot tell us about causation. For example, does a stronger affiliation with the LGB community expose individuals to a greater risk of discrimination or does a history of greater gay-related discrimination lead individuals to strengthen their identification with 
the LGB community? Following individuals over time would allow us to better answer such questions.

Despite the potential limitations of a cross-sectional survey, the research presented here makes several important contributions. From a theoretical perspective, this research extends our understanding of the exposure-reactivity model of stress (Bolger \& Zuckerman, 1995) in a couple of meaningful ways. First, the current data test the exposurereactivity model using a new class of stressors. In their original work, Bolger and Zuckerman (1995) examined the exposure-reactivity model within the context of major life events and daily hassles. In contrast, this research demonstrates the applicability of the exposure-reactivity model in the context of minority stress, specifically gay-related stress. Second, our data suggest that trait-like variables beyond personality can relate to both stress exposure and reactivity. The data make clear that social identity, which is conceived of as a relatively stable construct, is related to the amounts and types of gay-related stressors gay and lesbian individuals experience as well as how they respond to these stressors.

In extending the exposure-reactivity model, these data also add to our understanding of the stress process for gay and lesbian individuals. Over many years and many studies, research has consistently demonstrated a link between exposure to gay-related stressors and negative mental health outcomes for sexual minorities. Logic and anecdotal evidence suggest, however, that not all gay men and lesbians experience negative outcomes in the face of gay-related stress. Despite this assumption, little is known about the factors that predict such individual differences. Our research shows that social identity, specifically a sense of belonging to the LGB community, alters the stress process for gay and lesbian individuals. Obviously, this is only one potential moderating variable, and more research is needed to better understand the myriad factors such as social support, degree of identity disclosure and personality that predict whether gay and lesbian individuals experience gayrelated stressors and then how they respond in the face of such stressors.

\section{Acknowledgements}

This research was made possible through several grants awarded to the first author: a National Institute of Mental Health (NIMH) sponsored NRSA Predoctoral Fellowship, The Society for the Psychological Study of Social Issues (SPSSI) Grant-in-Aid Award and a Dissertation Year Fellowship provided by the Graduate Division and the University of California, Los Angeles (UCLA).

The research presented in this article was part of the first author's doctoral dissertation. The authors thank Paul G. Davies, Eric Vilain, Hector Myers and Christia Spears Brown for their helpful comments throughout the research process.

\section{Notes}

1. Throughout, the term gay-related stressors will be used to refer to the unique set of stressors experienced not only by gay men but by other sexual minority individuals, including lesbian women, as well. The broad terms 'gay stressor' and 'gay-related stressor' are the accepted terms in this line of research (see Lewis et al., 2001; Lewis, Derlega, Griffin, \& Krowinski, 2003; Rosario, Schrimshaw, Hunter, \& Gwadz, 2002).

2. The broad term 'gay identity' refers to the social identity experienced by both gay men and lesbian women. The use of this term follows from others' similar use of the generic term 'gay' to refer to a wide spectrum of sexual minority individuals. For example, in her pioneering book, Positively Gay, Betty Berzon (1979) used the umbrella term to refer to experiences of both gay men and lesbians. More recently, Ritch Savin-Williams (2005) described modern sexual minority adolescents, both male and female, as the 'New Gay Teenager'.

3. The authors of a study of gay men in Flanders, Belgium (Vincke, De Rycke, \& Bolton, 1999), suggested that their research tested this moderation hypothesis and failed to find support for it. 
However, their operationalisation of gay identity was very limited and did not assess this construct in ways that are consistent with accepted conceptualisations of social identity. Specifically, the authors assessed the identity with two items: 'I wish I was not gay' and 'I would not like to change my homosexuality even if I could'. These items are similar to common operationalisations of internalised homophobia, one of Meyer's proximal stressors, and may therefore better capture stress as opposed to identity.

4. Separate analyses were run for men and women and revealed identical patterns. In three instances, the results for lesbian women were only marginally significant $(p<.10)$ because of the lack of power.

\section{Notes on contributors}

Dr. Adam Fingerhut graduated from Stanford University with a B.A. in Psychology and then received his Ph.D. in Social Psychology from University of California, Los Angeles (UCLA) in 2007. He is currently an Assistant Professor in the Department of Psychology at Loyola Marymount University in Los Angeles, CA, USA. Using a variety of research methods including experiments, surveys and daily diaries, Adam examines the interplay between majority and minority groups. His research addresses two broad questions: (1) How are minority group members affected by their minority identity and social status? (2) What factors affect how majority group members perceive and interact with individuals from minority social groups? Adam's research has been funded by The National Institute of Mental Health (NIMH), The Society for the Psychological Study of Social Issues (SPSSI) and The Williams Institute on Sexual Orientation Law and Public Policy.

Dr. Letitia Anne Peplau is Professor of Social Psychology at the University of California, Los Angeles, CA, USA. She is a past president of the International Society for the Study of Personal Relationships. Anne was the 1997 recipient of the Distinguished Scientific Achievement Award from the Society for the Scientific Study of Sexuality and the 2002 Distinguished Scientific Contribution Award from the Society for the Psychological Study of Gay and Lesbian Issues (APA Division 44). She has published many research papers on gender and close relationships, including studies of heterosexual, lesbian and gay male relationships.

Dr. Shelly Gable received a B.A. in Psychology from Muhlenberg College and a Master of Arts in Psychology from the College of William \& Mary. She earned her Ph.D. in Social Psychology at the University of Rochester in 2000. She began her career in 2000 as an Assistant Professor at the UCLA where she earned tenure and co-founded the Interdisciplinary Relationship Science Program before joining the faculty at the University of California, Santa Barbara, in January 2007. Dr. Gable's research focuses on motivation, close relationships and positive emotions. Her work has been funded by the National Institutes of Health, the National Science Foundation and the Positive Psychology Network. She is currently funded by a National Science Foundation CAREER grant for newer investigators. She serves on the editorial board of several journals and received a distinguished teaching award from the Psychology Department at UCLA. In 2005 she received the Early Career Award from the Close Relationships Group of the Society for Personality and Social Psychology; and in 2006 she received the Presidential Early Career Award for Scientists and Engineers (PECASE) from President George W. Bush.

\section{References}

Aiken, L.S., \& West, S.G. (1991). Multiple regression: Testing and interpreting interactions. Thousand Oaks, CA: Sage.

Berzon, B. (1979). Developing a positive gay identity. In B. Berzon \& R. Leighton (Eds.), Positively gay (pp. 1-14). Millrose, CA: Celestial Arts.

Bolger, N., \& Zuckerman, A. (1995). A framework for studying personality in the stress process. Journal of Personality and Social Psychology, 69, 890-902.

Brooks, V.R. (1981). Minority stress and lesbian women. Lexington, MA: D.C. Heath.

Cochran, S.D. (2001). Emerging issues in research on lesbians' and gay men's mental health: Does sexual orientation really matter? American Psychologist, 56, 931-947.

diPlacido, J. (1998). Minority stress among lesbians, gay men and bisexuals. In G.M. Herek (Ed.), Stigma and sexual orientation (Vol. 4, pp. 138-159). Thousand Oaks, CA: Sage. 
Dodge, B., \& Sandfort, T.G.M. (2007). A review of mental health research on bisexual individuals when compared to homosexual and heterosexual individuals. In B.A. Firestein (Ed.), Becoming visible (pp. 28-51). New York, NY: Columbia University Press.

Fingerhut, A.W., Peplau, L.A., \& Ghavami, N. (2005). A dual-identity framework for understanding lesbian experience. Psychology of Women Quarterly, 29, 129-139.

Frable, D.E.S., Wortman, C., \& Joseph, J. (1997). Predicting self-esteem, well-being, and distress in a cohort of gay men: The importance of cultural stigma, personal visibility, community networks, and positive identity. Journal of Personality, 65, 599-624.

Herek, G.M., \& Garnets, L.D. (2007). Sexual orientation and mental health. Annual Review of Clinical Psychology, 3, 353-375. doi: 10.1146/annurev.clinpsy.3.022806.091510

Hong, Y., Morris, M.W., Chiu, C., \& Benet-Martínez, V. (2000). Multicultural minds: A dynamic constructivist approach to culture and cognition. American Psychologist, 55, 709-720. doi: 10.1037//0003-066X.55.7.709

Huebner, D.M., Rebchook, G.M., \& Kegeles, S.M. (2004). Experiences of harassment, discrimination, and physical violence among young gay and bisexual men. American Journal of Public Health, 94, 1200-1203.

Landrine, H., \& Klonoff, E.A. (1996). The schedule of racist events: A measure of racial discrimination and a study of its negative physical and mental health consequences. Journal of Black Psychology, 22, 144-168.

Lewis, R.J., Derlega, V.J., Berndt, A., Morris, L.M., \& Rose, S. (2001). An empirical analysis of stressors for gay men and lesbians. Journal of Homosexuality, 42, 63-88.

Lewis, R.J., Derlega, V.J., Griffin, J.L., \& Krowinski, A.C. (2003). Stressors for gay men and lesbians: Life stress, gay-related stress, stigma consciousness, and depressive symptoms. Journal of Social \& Clinical Psychology, 22, 716-729.

Link, B.G. (1987). Understanding labeling effects in the area of mental disorders: An assessment of the effects of expectations of rejection. American Sociological Review, 52, 96-112.

Mays, V.M., \& Cochran, S.D. (2001). Mental health correlates of perceived discrimination among lesbian, gay and bisexual adults in the United States. American Journal of Public Health, 91, 1869-1876.

Meyer, I.H. (1995). Minority stress and mental health in gay men. Journal of Health and Social Behavior, 36, 38-56.

Meyer, I.H. (2003). Prejudice, social stress and mental health in lesbian, gay and bisexual populations: Conceptual issues and research evidence. Psychological Bulletin, 129, 674-697. doi: 10.1037/0033-2909.129.5.674

Mossakowski, K.N. (2003). Coping with perceived discrimination: Does ethnic identity protect mental health? Journal of Health and Social Behavior, 44, 318-331.

Neblett, E.W., Jr., Shelton, J.N., \& Sellers, R.M. (2004). The role of racial identity in managing daily racial hassles. In G. Philogène (Ed.), Racial identity in context: The legacy of Kenneth B. Clark. Decade of behavior. Washington, DC: American Psychological Association.

Ortiz, D.J. (2001). Confessions of a mask: Identity management and disclosure of a concealable stigma (Unpublished doctoral dissertation). University of California, Los Angeles, CA.

Phinney, J.S. (1992). The multigroup ethnic identity measure: A new scale for use with diverse groups. Journal of Adolescent Research, 7, 156-176.

Radloff, L.S. (1977). The CES-D scale: A self report depression scale for research in the general population. Applied Psychological Measurement, 1, 385-401.

Roberts, R.E., Phinney, J.S., Masse, L.C., Chen, Y.R., Roberts, C.R., \& Romero, A. (1999). The structure of ethnic identity of young adolescents from diverse ethnocultural groups. The Journal of Early Adolescence, 19, 301-322.

Robin, L., Brener, N.D., Donahue, S.F., Hack, T., Hale, K., \& Goodenow, C. (2002). Associations between health risk behaviors and opposite-, same-, and both-sex sexual partners in a representative sample of Vermont and Massachusetts high school students. Archives of Pediatrics and Adolescent Medicine, 156, 349-355.

Rosario, M., Schrimshaw, E.W., Hunter, J., \& Gwadz, M. (2002). Gay-related stress and emotional distress among gay, lesbian and bisexual youths: A longitudinal examination. Journal of Consulting and Clinical Psychology, 70, 967-975.

Savin-Williams, R.C. (2005). The new gay teenager. Cambridge, MA: Harvard University Press.

Schmader, T. (2002). Gender identification moderates stereotype threat effects on women's math performance. Journal of Experimental Social Psychology, 38, 194-201. doi: 10.1006/jesp. 2001.1500 
Sellers, R.M., Caldwell, C., Schmeelk-Cone, K.H., \& Zimmerman, M.A. (2003). Racial identity, racial discrimination, perceived stress, and psychological distress among African American young adults. Journal of Health and Social Behavior, 44, 302-317.

Sellers, R.M., \& Shelton, J.N. (2003). The role of racial identity in perceived racial discrimination. Journal of Personality and Social Psychology, 84, 1079-1092. doi: 10.1037/0022-3514. 84.5.1079

Selvidge, M.M.D. (2001). The relationship of sexist events, heterosexist events, self-concealment and self-monitoring to psychological well-being in lesbian and bisexual women (Unpublished doctoral dissertation). Memphis State University, Memphis, TN.

Steele, C.M., \& Aronson, J. (1995). Stereotype threat and the intellectual test performance of African Americans. Journal of Personality and Social Psychology, 69, 797-811.

Swim, J.K., Pearson, N.B., \& Johnston, K. (2004). Day to day experiences with heterosexism: Heterosexist hassles as daily stressors. Unpublished manuscript.

Szymanski, D.M. (2009). Examining potential moderators of the link between heterosexist events and gay and bisexual men's psychological distress. Journal of Counseling Psychology, 56, 142-151. doi: $10.1037 / 0022-0167.56 .1 .142$

Tajfel, H., \& Turner, J.C. (1979). An integrative theory of intergroup conflict. In W.G. Austin \& S. Worschel (Eds.), The social psychology of intergroup relations (pp. 33-47). Monterey, CA: Brooks/Cole.

Theuninck, A.C. (2000). The traumatic impact of minority stressors on males self-identified as homosexual or bisexual (Unpublished doctoral dissertation). University of Witwatersrand, Johannesburg, South Africa.

Udry, J.R., \& Chantala, K. (2002). Risk assessment of adolescents with same-sex relationships. Journal of Adolescent Health, 31, 84-92.

Vincke, J., De Rycke, L., \& Bolton, R. (1999). Gay identity and the experience of gay social stress. Journal of Applied Social Psychology, 29, 1316-1331.

Waldo, C.R. (1999). Working in majority context: A structural model of heterosexism as minority stress in the workplace. Journal of Counseling Psychology, 46, 1-15. 
Copyright of Psychology \& Sexuality is the property of Routledge and its content may not be copied or emailed to multiple sites or posted to a listserv without the copyright holder's express written permission. However, users may print, download, or email articles for individual use. 